\title{
Prevalence of Pre-Diabetes among Adults Attending Primary Health Care Centers, Makkah City, Saudi Arabia
}

\author{
Yousef Mohammed Turki ${ }^{\star *}$, Amal A. Hegazy ${ }^{2,3}$, Bahaa Abdulrahman Abaalkhail ${ }^{2}$ \\ 1Preventive Medicine Department, Public Health Affairs, Makkah, Saudi Arabia. \\ 2Department of Family and Community Medicine, \\ Faculty of Medicine, King Abdulaziz University, Jeddah, Saudi Arabia. \\ ${ }^{3}$ Department of Community and Occupational Medicine, \\ Faculty of Medicine (For Girls), Al-Azhar University, Cairo, Egypt.
}

\begin{abstract}
Background: Diabetes mellitus has become a worldwide pandemic and is causing huge costs and burdens upon patients as well as health care givers. There is increasing evidence that lifestyle alterations are extremely effective in delaying the onset of pre-diabetes or development from prediabetes to type-2 diabetes mellitus.

Objectives: To determine the prevalence rate of pre-diabetes among adult population attending a reference primary health care center (PHCC) in Makkah city, to identify sociodemographic, lifestyle, medical factors and to describe knowledge and attitude toward pre-diabetes among the studied population.
\end{abstract}

Material and methods: A cross-sectional study that carried out on 250 adult participants in Makkah over a period of two months and half. Data collected by an interviewed Questionnaire, anthropometric measurements and laboratory investigation.

Results: The prevalence rate of pre-diabetes in our study is $17.3 \%$. There was a statistically significant difference between pre-diabetic and normal groups regarding history of hypertension. Prevalence of pre-diabetes was higher in adults with physical inactivity $(23.3 \%)$, obesity (high body mass index) $(28.1 \%)$ and central obesity (high waist circumference) (29.4\%). Using multiple logistic regressions, we observed that total energy; eating sweets are also significant predictors among pre-diabetes group.

\section{INTRODUCTION}

Pre-diabetes is a worldwide health problem. It produces no symptoms but is a major risk factor for developing type-2 diabetes mellitus and its complications, which include renal failure, heart disease, stroke, and retinopathy. ${ }^{1-5}$

The American Diabetes Association (ADA) identified people with pre-diabetes, defined as impaired fasting glucose (IFG), impaired glucose tolerance (IGT) or high $\mathrm{HbA1c}$, as a group at high risk for developing diabetes. ${ }^{6-7}$ The standard value for pre-diabetes is a blood glucose level of $100-125 \mathrm{mg} / \mathrm{dL}$ for fasting blood glucose (called IFG), 140 - $199 \mathrm{mg} / \mathrm{dL}$ for blood glucose two-hour post glucose load (called IGT) or HbA1c between $5.7 \%$ to $6.4 \%{ }^{8}$

Pre-diabetes is a term that refers to the stage at which a person is between normal blood sugar levels and diabetic blood sugar
Conclusion: A high prevalence of pre-diabetes status was reported among the study group and it was associated with modifiable risk factors. Although it may be difficult to disentangle all possible explanations for the increase in prediabetes prevalence. This study highlights the importance of increasing awareness towards pre-diabetes and effective health education programs promoting regular exercise and healthy diet are needed to reduce the risk of pre-diabetes in Saudi Arabia that may lead to future decrease in the incidence of diabetes.

Keywords: Prediabetes; Risk factors; Prevalence; Type-2 diabetes mellitus.

\section{*Correspondence to:}

Yousef Mohammed Turki

Preventive Medicine Department,

Public Health Affairs, Makkah, Saudi Arabia.

Article History:

Received: 21-10-2016, Revised: 01-11-2016, Accepted: 16-11-2016

\begin{tabular}{|l|c|}
\hline \multicolumn{2}{|c|}{ Access this article online } \\
\hline $\begin{array}{l}\text { Website: } \\
\text { www.ijmrp.com }\end{array}$ & Quick Response code \\
\hline DOI: & \\
10.21276/ijmrp.2016.2.6.026 & \\
\hline
\end{tabular}

levels. When people are in the pre-diabetic stage, if they are able to lose ten percent of their body mass, they may be able to eliminate any chance of developing diabetes in the future - or at least postpone the diagnosis. Proper diagnosis of a patient in the pre-diabetic stage is a crucial intervention for lowering diabetes incidences, which allows patients to live a healthier life. ${ }^{9}$

The prevalence of pre-diabetes is, in fact, higher than the prevalence of diabetes..$^{10}$ It has been estimated that a pre-diabetic person is 5 to 15 times more likely to develop type-2 diabetes mellitus than a person with normal blood glucose levels. ${ }^{11,12}$

There is growing evidence that lifestyle modifications are extremely effective in delaying the onset of pre-diabetes or the progression from pre-diabetes to type-2 diabetes mellitus. ${ }^{13}$ 
According to the National Survey for Health Information 2013, in the Kingdom of Saudi Arabia, the prevalence of pre-diabetes was $17 \%$ among males and $15.5 \%$ among females. The total prevalence of diabetes was $14.8 \%$ among males and $11.7 \%$ among females. ${ }^{14}$

Lifestyle modification is particularly effective in preventing or delaying the progression to diabetes among individuals with a family history of diabetes. However, the International Diabetic Federation recommends that diabetes control programs simultaneously promote lifestyle modification among high-risk individuals and the entire population. ${ }^{15}$ The intake of dietary energy in excess of expenditure simply results in weight gain and increases the risk of T2DM. Physical inactivity has long been identified as a risk factor for T2DM independently of its effects on body size and dietary patterns. Physical activity of moderate to vigorous intensity and duration decreases the risk of conversion of impaired glucose tolerance to diabetes even in the absence of significant weight loss and independently of other risk factors. ${ }^{15}$

As there are no epidemiologic studies in Makkah city to investigate pre-diabetes and its associated risk factors, including knowledge and attitudes, this study was carried out to study prediabetes state as a potential health problem and to detect its predictors in the adult population in Makkah city, Saudi Arabia.

\section{MATERIAL AND METHODS}

The study took place in Makkah city, a city with approximately 2000,000 inhabitants and located in the western region of Saudi Arabia. This cross-sectional study was involved with 250 adult participants from 10 primary health care centers in Makkah city (these centers are geographically distributed across Makkah city) during the period from November 2014 to January 2015. Adult patients aged 18 years and above were eligible for the study.

A systematic random sampling technique was used to $t$ select every twentieth patient because the average rate of patients visiting a primary health care was approximately 100 patients per day. Thus, a total of 25-30 patients per week from 10 centers were recruited to collect the required sample size of approximately 250 cases. (Some modifications were done according to the number of patients who visited the centers per day).

After providing informed consent, all the studied male and female groups were administered an interview questionnaire by the principal investigator, who was accompanied by a female nurse for the interviews with female subjects for cultural reasons. Patients with a history of diabetes, those revealed with laboratory investigation to have $\mathrm{HbA} 1 \mathrm{c}$ more than $6.4 \%$ (diabetics), pregnant females (multiple factors lower $\mathrm{HbA} 1 \mathrm{c}$ during pregnancy), conditions with reduced red blood cell survival, such as hemoglobinopathy (sickle trait, sickle disease or thalassemia), Hemolytic anemia, severe blood loss, splenomegaly and antiretroviral drugs, may markedly lower $\mathrm{HbA} 1 \mathrm{c}$, patients with increased red blood cell survival may demonstrate increased $\mathrm{HbA1c}$, e.g., splenectomy, renal dialysis patients have a markedly reduced $\mathrm{HbA} 1 \mathrm{c}$, especially if treated with erythropoietin, iron and $\mathrm{B} 12$ deficiency and their treatment may raise or lower $\mathrm{HbA} 1 \mathrm{C}$ and liver disease patients were excluded from the study.

To calculate the sample size, we assumed that $16 \%$ of the adult population would have pre-diabetes based on the National Survey for Health Information in the Kingdom. ${ }^{16}$ To achieve this sample size at the $95 \%$ confidence level with an acceptable error of $5 \%$, at least 210 adults were required.

The data were collected by an interview questionnaire that includes three parts. The first part includes questions regarding the participants' personal characteristics and medical factors (age, gender, marital status, educational level, income, smoking history, family history of diabetes and personal history of hypertension). The second part includes questions about lifestyle, food consumption and physical activity. We used a semi-quantitative Food Frequency Questionnaire (FFQ) to assess the participants' dietary behaviors. ${ }^{17}$ This questionnaire is a simple tool that measures the frequency with which participants consumed essential common meals during the last year, ${ }^{18}$ using measurement models/portion size that help to quantify food intake. We selected common local food items (fruit juice, canned juice, carbonated drink with sugar, potatoes, vegetables, fruits, meal bread, lamb, beef, chicken, pizza, cake, sweets, sweets with chocolate, fast food, rice and pasta) that are relevant to our culture. Every participant had the choice of reporting the frequency per month, per week or per day. Finally, the principle investigator calculated the frequency per day for all participants. Additionally, we grouped relevant food items together for analysis and calculated the range of servings per day for these items. The groups are the canned drinks with sugar group (fuzzy drinks with sugar and canned juice), the bread group (rice, pasta and bread), meat groups (beef, lamb and chicken), sweets groups (sweets, sweet with chocolate and cake), fruits group (fresh fruits and fruit juice), vegetable group (fresh vegetables and potatoes), fast food group (fast foods and pizza).

In addition, we calculated the total energy consumption and the food compositions of these items using Walter Willet's food frequency method using food composition table, which includes total protein, total carbohydrate and total fat. Total energy produced by carbohydrates, proteins and fats were calculated separately. Then, we divided the range of these scores into five quantiles and grouped the second, third and fourth quantiles together for analysis. Nutrients were adjusted for age, sex and total calories.

Regarding physical activity, we used the validated General Practice Physical Activity Questionnaire [GPPAQ], ${ }^{19}$ which was developed by the London School of Hygiene and Tropical Medicine as a short measure of physical activity. This screening tool is used to assess adults' (16 - 74 years) physical activity levels and provides a 4-level Physical Activity Index (PAI) that categorizes subjects into one of the following categories: Inactive: Sedentary job and no physical exercise or cycling, moderately inactive: Sedentary job and some but $<1$ hour of physical exercise and/or cycling per week OR Standing job and no physical exercise or cycling, moderately active: Sedentary job and 1-2.9 hours of physical exercise and/or cycling per week OR Standing job and some but $<1$ hour of physical exercise and/or cycling per week OR Physical job and no physical exercise or cycling and active: Sedentary job and $\geq 3$ hours of physical exercise and/or cycling per week OR Standing job and 1-2.9 hours of physical exercise and/or cycling per week OR Physical job and some but < 1 hour of physical exercise and/or cycling per week OR Heavy manual job. We grouped the active category with the moderate active category as active group and the moderate inactive with the 
inactive category as inactive group for analysis. The third part of the questionnaire concerns participants' knowledge of and attitudes toward pre-diabetes, which is constructed, based on American diabetes association standards of medical care 2015.20 The questionnaire included 15 statements regarding knowledge of pre-diabetes and 5 statements regarding attitudes toward diabetes. Participants were asked respond yes or no to the knowledge questions, and a 5-point Likert scale, ranging from "very highly agree" to "very highly disagree", was used for the statements regarding attitudes..$^{20,21} \mathrm{~A}$ language expert translated the original questionnaire into Arabic. This was followed by a backward translation into English by another language expert to ensure accuracy.

A trained nurse using standard procedures for male and female subjects took weight, height and waist circumference measurements and a blood sample. ${ }^{22}$

Height was measured without shoes to the nearest 0.01 centimeter on a stadiometer, and weight in kilograms was measured in light clothing on a level balance to the nearest 0.01 $\mathrm{kg}$ to obtain an accurate estimate of the true weight of individuals. The scale was checked for accuracy at frequent intervals. Body mass index (BMI) was calculated for each subject using the equation (weight $[\mathrm{kg}] /$ height $\left[\mathrm{m}^{2}\right]$ ). World Health Organization (WHO) criteria was used to classify people into underweight (BMI < $\left.18.5 \mathrm{~kg} / \mathrm{m}^{2}\right)$, normal-weight $\left(\mathrm{BMl}=18.5-24.9 \mathrm{~kg} / \mathrm{m}^{2}\right)$, overweight $\left(\mathrm{BMI}=25-29.9 \mathrm{~kg} / \mathrm{m}^{2}\right)$, and obese $\left(\mathrm{BMl} \geq 30 \mathrm{~kg} / \mathrm{m}^{2}\right)$ categories. ${ }^{23}$ Waist circumference was also measured by a trained nurse, who defined the top of the participant's hip bone and the bottom of his/her ribs and then asked his/her to breathe out normally. Then, the tape measure was placed midway between these points and wrapped around the participant's waist. Men with a waist measurement greater than $94 \mathrm{~cm}$ and women with a measurement greater than $80 \mathrm{~cm}$ were considered obese. ${ }^{24}$

We used $\mathrm{HbA} 1 \mathrm{c}$ to diagnose pre-diabetes because the $\mathrm{HbA} 1 \mathrm{c}$ test does not require fasting and blood can be drawn for the test at any time of day. Regarding the blood sample, a three-milliliter venous blood sample was drawn and collected in a glass tube containing EDTA from every participant, and a lab technician measured the level of $\mathrm{HbA} 1 \mathrm{c} \%$. Then, the glass tubes were kept in a rack and stored at $4^{\circ} \mathrm{C}$ in a refrigerator. Then, the tubes were transported in storage box that contained icepacks to AlKaakiah primary health care center, where analysis was performed at the same day by a lab technician using The Siemens Dimension ${ }^{\circledR}$ Xpand Plus chemistry analyzer, which is reliable, valid and certified by the National Glycohemoglobin standardization program (NGSP) for the analysis of $\mathrm{HbA} 1 \mathrm{c} .{ }^{25,}{ }^{26}$ The laboratory results $(\mathrm{HbA} 1 \mathrm{c} \%)$ were recorded by the principal investigator.

Ethical approval was obtained from the Institutional Review Board of the King Abdulaziz University, and official approval letters were obtained from the Directorate of Health Affairs in Makkah city. The study takes into account the Helsinki Declaration for the rights and interests of the participants.

The collected data were coded, entered, cleaned, and analyzed using SPSS software, version 16. The data were double checked (Ensuring the accuracy of the data is critical to any analysis that follows). Data were presented using descriptive statistics in the form of frequencies and percentages for categorical variables. Chi-square test was used for categorical variables. Univariate regression was done for demographic variables with adjustment for gender age and was done for food items and total energy with adjustment of age, gender and total energy. Multivariate logistic regression model was used to explore independent risk factors, with a $95 \%$ level of confidence. (The level of significance was set at $P<0.05$.).

Table 1: Demographic characteristics of the study group (normal and pre-diabetes).

\begin{tabular}{lcc}
\hline Variables & Normal(n=186) & Pre-diabetes ( $\mathbf{n}=39)$ \\
\hline Gender & $\mathbf{N}(\%)$ & $14(14.3)$ \\
Male & & $25(19.6)$ \\
Female & $102(80.3)$ & \\
Age & & $5(8.2)$ \\
$18-29$ years & $56(91.8)$ & $17(19.3)$ \\
$30-39$ years & $71(80.7)$ & $17(22.3)$ \\
40-70 years & $59(77.6)$ & $8(13)$ \\
Marital status & & $27(18.9)$ \\
Single & $54(87.0)$ & $4(20)$ \\
Married & $116(81.1)$ & $16(18.6)$ \\
Divorced or widowed & $16(80)$ & $19(18.0)$ \\
Income & & $4(11.7)$ \\
Below average (<5000 SR/month) & $70(81.4)$ & $14(17.5)$ \\
Average (5000-10000 SR/month) & $86(81.9)$ & $25(17.2)$ \\
Above average (> 10000 SR/month) & $30(88.2)$ & \\
Smoking & & $3(21.4)$ \\
Smoker & $66(82.5)$ & $20(24.1)$ \\
Non-smoker & $120(82.7)$ & $16(12.5)$ \\
Educational level & & \\
Low educational level & $11(78.6)$ & $3(47.4)$ \\
Moderate educational level & $63(75.9)$ & $30(14.5)$ \\
High educational level & $112(87.5)$ & \\
Hypertension & $10(52.6)$ & \\
Yes & $176(85.4)$ & \\
No & & \\
\hline
\end{tabular}


Table 2: Predictors of pre-diabetes among studies group.

\begin{tabular}{|c|c|c|c|}
\hline Variables & $\overline{\text { OR }}$ & $95 \%$ C.I & $p$-value \\
\hline Gender & 0.986 & $0.402-2.420$ & 0.975 \\
\hline \multicolumn{4}{|l|}{ Age } \\
\hline $18-29$ & 1.0 & -.-- & \\
\hline $30-39$ years & 1.601 & $0.460-5.570$ & 0.670 \\
\hline $40-70$ years & 1.141 & $0.303-4.292$ & \\
\hline Total energy & & ---- & \\
\hline 1stquantile & 1.0 & $0.590-6.453$ & $0.010^{* *}$ \\
\hline $2^{\text {nd }}$ to $4^{\text {th }}$ quantile & 1.952 & $2.545-104.21$ & \\
\hline $5^{\text {th }}$ quantile & 16.287 & & \\
\hline \multicolumn{4}{|l|}{ Eating Sweets } \\
\hline$<1$ time & 1.0 & -.-- & \\
\hline $1-3$ times & 1.353 & $0.507-3.611$ & 0.007 ** \\
\hline$>3$ times & 0.064 & $0.009-.464$ & \\
\hline Hypertension & 4.432 & $1.203-16.321$ & $0.025^{* *}$ \\
\hline Physical activity & 2.915 & $1.131-7.514$ & 0.027 ** \\
\hline \multicolumn{4}{|l|}{ BMI } \\
\hline Normal & 1.0 & -.--- & \\
\hline Overweight & 0.735 & $0.211-2.553$ & \\
\hline Obese & 0.653 & $0.171-2.490$ & 0.821 \\
\hline Waist circumference & 42.512 & $7.372-245.14$ & $0.001^{* *}$ \\
\hline
\end{tabular}

Table 3: Comparison between normal and pre-diabetes regarding their knowledge about pre-diabetes.

\begin{tabular}{|c|c|c|c|c|}
\hline Knowledge statement & $\begin{array}{l}\text { Normal }(\mathrm{n}=186) \\
\mathrm{N}(\%)\end{array}$ & $\begin{array}{l}\text { Pre-diabetes } \\
(n=39) N(\%)\end{array}$ & $\mathrm{X}^{2}$ & $p$-value \\
\hline \multicolumn{5}{|c|}{ I know that there is a condition called "pre-diabetes" } \\
\hline Yes & $103(83.7)$ & $20(16.3)$ & 0.21 & 0.64 \\
\hline No & $83(81.4)$ & $19(18.6)$ & & \\
\hline \multicolumn{5}{|c|}{ The frequency of pre-diabetes is higher than that of diabetes. } \\
\hline Yes & $84(80.8)$ & $20(16.3)$ & 0.48 & 0.48 \\
\hline No & $102(84.3)$ & $19(18.6)$ & & \\
\hline \multicolumn{5}{|c|}{$\begin{array}{l}\text { As standard, Blood glucose levels of } 100-125 \mathrm{mg} / \mathrm{dl} \text { after an } \\
\text { overnight or eight-hour fast may indicate pre-diabetes. }\end{array}$} \\
\hline Yes & $81(82.7)$ & $17(17.3)$ & 0.00 & 0.99 \\
\hline No & $105(82.7)$ & $22(17.3)$ & & \\
\hline \multicolumn{5}{|c|}{$\begin{array}{l}140-199 \mathrm{mg} / \mathrm{dL} \text { for blood glucose two hour post glucose load } \\
\text { is a standard value to diagnose pre-diabetes. }\end{array}$} \\
\hline Yes & $61(83.6)$ & $12(16.4)$ & 0.06 & 0.80 \\
\hline No & $125(82.2)$ & $27(17.8)$ & & \\
\hline \multicolumn{5}{|c|}{$\begin{array}{l}\text { Anyone who is pre-diabetic has a strong increased risk of being } \\
\text { diagnosed with diabetes mellitus in few years. }\end{array}$} \\
\hline Yes & $93(83.0)$ & $19(17.0)$ & 0.02 & 0.88 \\
\hline No & $93(82.3)$ & $20(17.7)$ & & \\
\hline \multicolumn{5}{|c|}{$\begin{array}{l}\text { Diagnosis and management of pre-diabetes early will prevent or } \\
\text { prolong the onset of diabetes in the future. }\end{array}$} \\
\hline Yes & $114(86.4)$ & $18(13.6)$ & 3.04 & 0.08 \\
\hline No & $72(77.4)$ & $21(22.6)$ & & \\
\hline \multicolumn{5}{|c|}{ Pre-diabetes is more common among obese people. } \\
\hline Yes & $48(84.2)$ & $9(15.8)$ & 0.12 & 0.72 \\
\hline No & $138(82.1)$ & $30(17.9)$ & & \\
\hline \multicolumn{5}{|c|}{ Lack of physical activity is a strong risk factor for pre-diabetes } \\
\hline Yes & $115(87.1 \%)$ & $17(12.9)$ & 4.42 & $0.03^{*}$ \\
\hline No & $71(76.3 \%)$ & $22(23.7)$ & & \\
\hline \multicolumn{5}{|c|}{$\begin{array}{l}\text { Hypertensive ( } B P \geq 140 / 90 \text { ) patients are more likely to be pre- } \\
\text { diabetic thanNormotensive ( } B P<140 / 90 \text { ) persons. }\end{array}$} \\
\hline Yes & $59(76.6)$ & $18(23.4)$ & 2.98 & 0.08 \\
\hline No & $127(85.8)$ & $21(14.2)$ & & \\
\hline \multicolumn{5}{|c|}{$\begin{array}{l}\text { Eating too much sugar and other sweet foods is a cause of pre- } \\
\text { diabetes. }\end{array}$} \\
\hline Yes & $116(84.7)$ & $21(15.3)$ & 0.98 & 0.32 \\
\hline No & $70(79.5)$ & $18(20.5)$ & & \\
\hline
\end{tabular}




\begin{tabular}{|c|c|c|c|c|c|}
\hline \multicolumn{6}{|l|}{ Central obesity is a risk factor for pre-diabetes. } \\
\hline \multirow{2}{*}{\multicolumn{2}{|c|}{$\begin{array}{l}\text { Yes } \\
\text { No }\end{array}$}} & $55(85.9)$ & $9(14.1)$ & 0.66 & 0.41 \\
\hline & & $131(81.4)$ & $30(18.6)$ & & \\
\hline \multicolumn{6}{|c|}{$\begin{array}{l}\text { The risk of cardiovascular disease is higher among pre- } \\
\text { diabetics compared to individuals with normal glucose levels. }\end{array}$} \\
\hline \multicolumn{2}{|c|}{ Yes } & $81(81.0)$ & $19(19.0)$ & 0.34 & 0.55 \\
\hline No & & $105(84.0)$ & $20(16.0)$ & & \\
\hline \multicolumn{6}{|l|}{ Smoking is a strong risk factor for pre-diabetes. } \\
\hline \multicolumn{2}{|l|}{ Yes } & $91(85.0)$ & $16(15.0)$ & 0.80 & 0.36 \\
\hline \multirow{2}{*}{\multicolumn{6}{|c|}{$\begin{array}{l}\text { No } \\
\text { Pre-diabetes can be cured. }\end{array}$}} \\
\hline & & & & & \\
\hline & $114(85.1)$ & $20(14.9)$ & 1.34 & 0.24 \\
\hline No & & $72(79.1)$ & $19(20.9)$ & & \\
\hline \multicolumn{6}{|l|}{ Pre-diabetes can be treated by oral medication. } \\
\hline \multicolumn{2}{|l|}{ Yes } & $81(86.2)$ & $13(13.8)$ & 1.38 & 0.24 \\
\hline \multicolumn{2}{|l|}{ No } & $105(80.2)$ & $26(19.8)$ & & \\
\hline \multicolumn{6}{|c|}{ Table 4: Comparison between normal and pre-diabetes regarding their attitude toward pre-diabetes. } \\
\hline \multicolumn{2}{|c|}{ Attitude questions } & $\begin{array}{l}\text { Pre-diabetes } \\
(n=39) N(\%)\end{array}$ & $\begin{array}{l}\text { Normal }(n=186) \\
\quad N(\%)\end{array}$ & & $\begin{array}{c}\chi^{2} \\
\text { (P value) }\end{array}$ \\
\hline $\begin{array}{l}\text { - Pre-diabetes is a serious condition if not } \\
\text { properly managed. }\end{array}$ & $\begin{array}{l}\text { Agree } \\
\text { Neutral } \\
\text { disagree }\end{array}$ & $\begin{array}{c}34(17.2) \\
4(16.0) \\
1(50.0)\end{array}$ & $\begin{array}{c}164(82.8) \\
21(84.0) \\
1(50.0)\end{array}$ & & $.148^{*}(0.563)$ \\
\hline \multicolumn{2}{|c|}{$\begin{array}{l}\text { - Properly diagnosing a patient in the pre- Agree } \\
\text { diabetic stage is crucial to lowering the Neutral } \\
\text { development of diabetes, which allows patients disagree } \\
\text { to live a healthier life. }\end{array}$} & $\begin{array}{l}38(18.2) \\
0(0.00) \\
1(50.0)\end{array}$ & $\begin{array}{c}171(81.8) \\
14(100) \\
1(50.0)\end{array}$ & \multicolumn{2}{|c|}{$6.547^{*}(0.038)$} \\
\hline \multirow{2}{*}{$\begin{array}{l}\text { The lack of pre-diabetes guidance and the } \\
\text { screening on diabetes creates the condition } \\
\text { that makes pre-diabetes goes unknown and } \\
\text { unwatched. } \\
\text { - Pre-diabetes is an important problem in Saudi } \\
\text { Arabia. }\end{array}$} & $\begin{array}{l}\text { Agree } \\
\text { Neutral } \\
\text { disagree }\end{array}$ & $\begin{array}{l}30(17.3) \\
4(19.0) \\
5(16.1)\end{array}$ & $\begin{array}{c}143(82.7) \\
17(81.0) \\
26(83.9)\end{array}$ & \multicolumn{2}{|c|}{$0.074^{*}(0.964)$} \\
\hline & $\begin{array}{l}\text { Agree } \\
\text { Neutral } \\
\text { disagree }\end{array}$ & $\begin{array}{c}24(21.6) \\
3(11.5) \\
12(13.6)\end{array}$ & $\begin{array}{l}87(78.4) \\
23(88.5) \\
76(86.4)\end{array}$ & & $.910^{*}(0.233)$ \\
\hline - Pre-diabetes is a preventable condition. & $\begin{array}{l}\text { Agree } \\
\text { Neutral } \\
\text { disagree }\end{array}$ & $\begin{array}{l}32(16.7) \\
5(19.2) \\
2(25.0)\end{array}$ & $\begin{array}{c}159(83.3) \\
21(80.8) \\
6(75.0)\end{array}$ & \multicolumn{2}{|c|}{$0.406^{*}(0.816)$} \\
\hline
\end{tabular}

${ }^{*}$ Fisher Exact test

\section{RESULTS}

The total number of participants in this study was 250 . We excluded a total of 25 subjects due to missing data and being diabetics $(\mathrm{HgA} 1 \mathrm{c}>6.4)$. Thus our study based on 225 subjects. Table 1 demonstrates the demographic characteristics of the study groups. About (19.6\%) of females had pre-diabetes. (22.3\%) of Age group between 40-70 years had pre-diabetes. About (20\%) of divorced and widowed groups had pre-diabetes. (18\%) of prediabetes had average income and (17.5\%) of smokers had prediabetes. Also $(24.1 \%)$ of moderate educational level had prediabetes and (47.4\%) patients with a history of hypertension had pre-diabetes. Figure 1 shows more than half $(53.8 \%)$ of prediabetes had 1st degree relative's history of diabetes compared to $(37.1 \%)$ of normal group. Most of pre-diabetic cases are overweight $(41 \%)$ and obese $(41 \%)$ in comparison to normal group (39.2\% and $22 \%$, respectively) as shown in figure 3 .

The prevalence rate of pre-diabetes in our study was $17.3 \%$. About (23.3\%) of physical inactive group had pre-diabetes and the difference was statistical significant $(p=0.011)$ between normal and pre-diabetes group.In addition, the table shows that there was a statistically significant difference between pre-diabetic and normal groups regarding BMI ( $p=0.014)$, waist circumference $(p=0.001)$.In addition $(28.1 \%)$ of obese participants had pre- diabetes and (29.4\%)of participants with increased waist had prediabetes.

There was a statistically significant difference between prediabetic and normal groups regarding hypertension $(p=0.001)$ and about $(23.3 \%)$ of participants with history of hypertension had pre-diabetes. While in other personal characteristics, there were no statistical significant difference. Also, there is no significant difference between pre-diabetes and normal regarding total energy and total energy produced by carbohydrate, protein and fat.

The simple logistic regression analysis suggests that total energy, sweet eating, hypertension, physical activity and waist circumference are the most significant regression coefficients among other predictors. (Table 2)

Table 3 shows there is no statistical significant difference between study groups regarding knowledge exept for statement (Lack of physical activity is a strong risk factor for pre-diabetes ), $p$ value (0.03). Table 4 shows that there is no statistically significant difference between pre-diabetes and individual regarding all attitude statements. As shown in figure 3 most of pre-diabetic group were more inactive and moderately inactive in comparison to normal group. 
Yousef Mohammed Turki et al. Pre-Diabetes among Adults in Saudi Arabia

Figure 1: Frequency of $1^{\text {st }}$ degree relatives of diabetes in both groups.

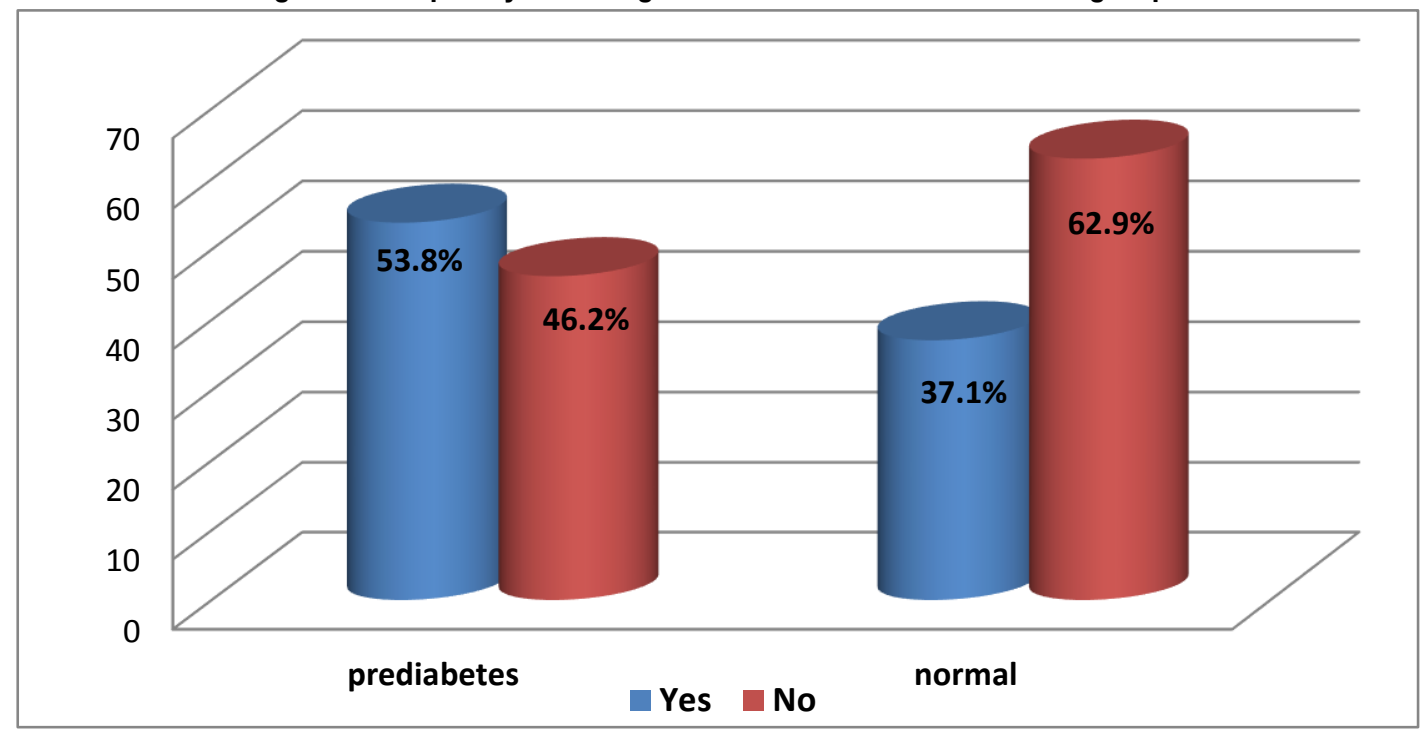

Figure 2: Frequency of body mass index grade in the study groups.

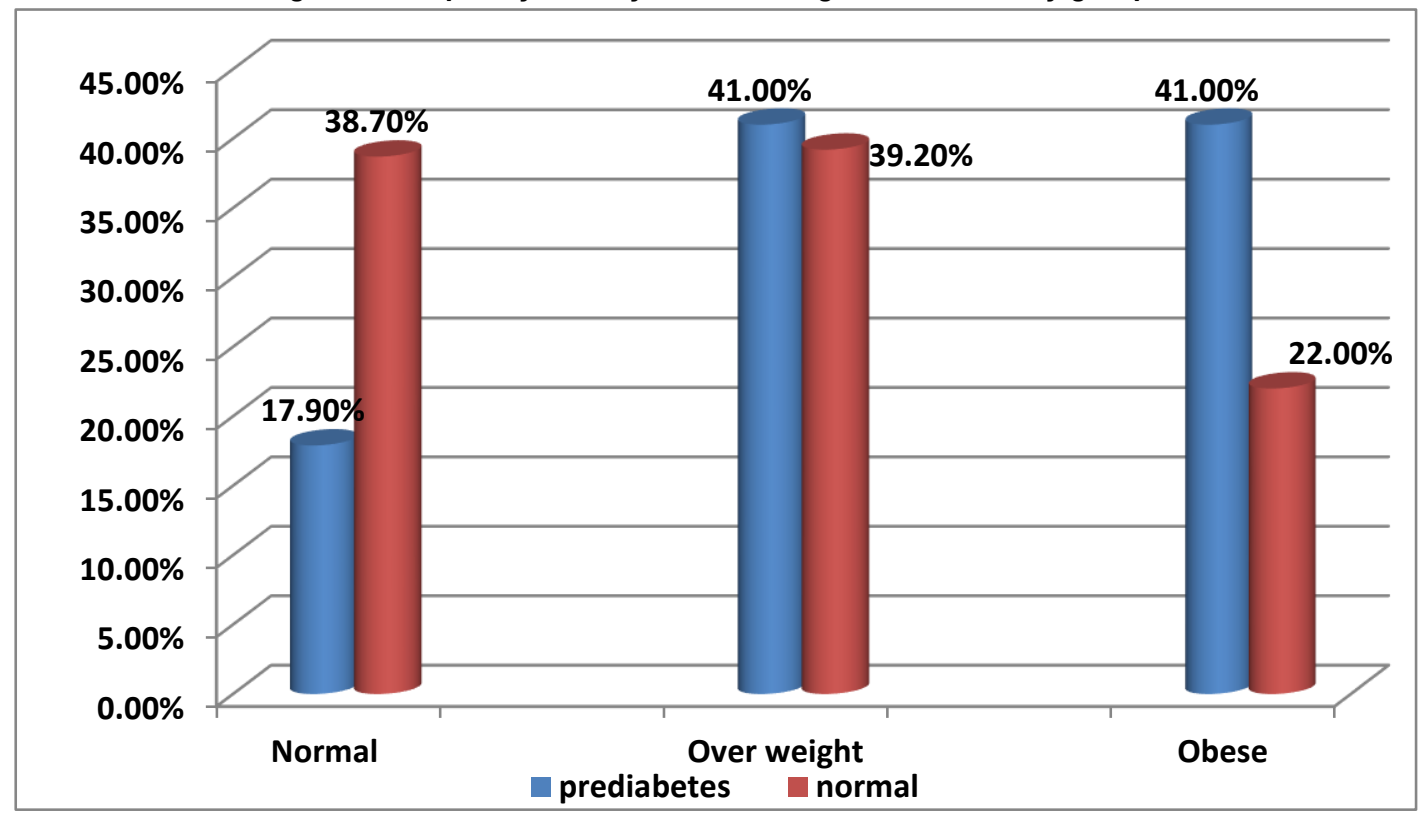

Figure 3: Frequency of physical activity index grade in the study groups.

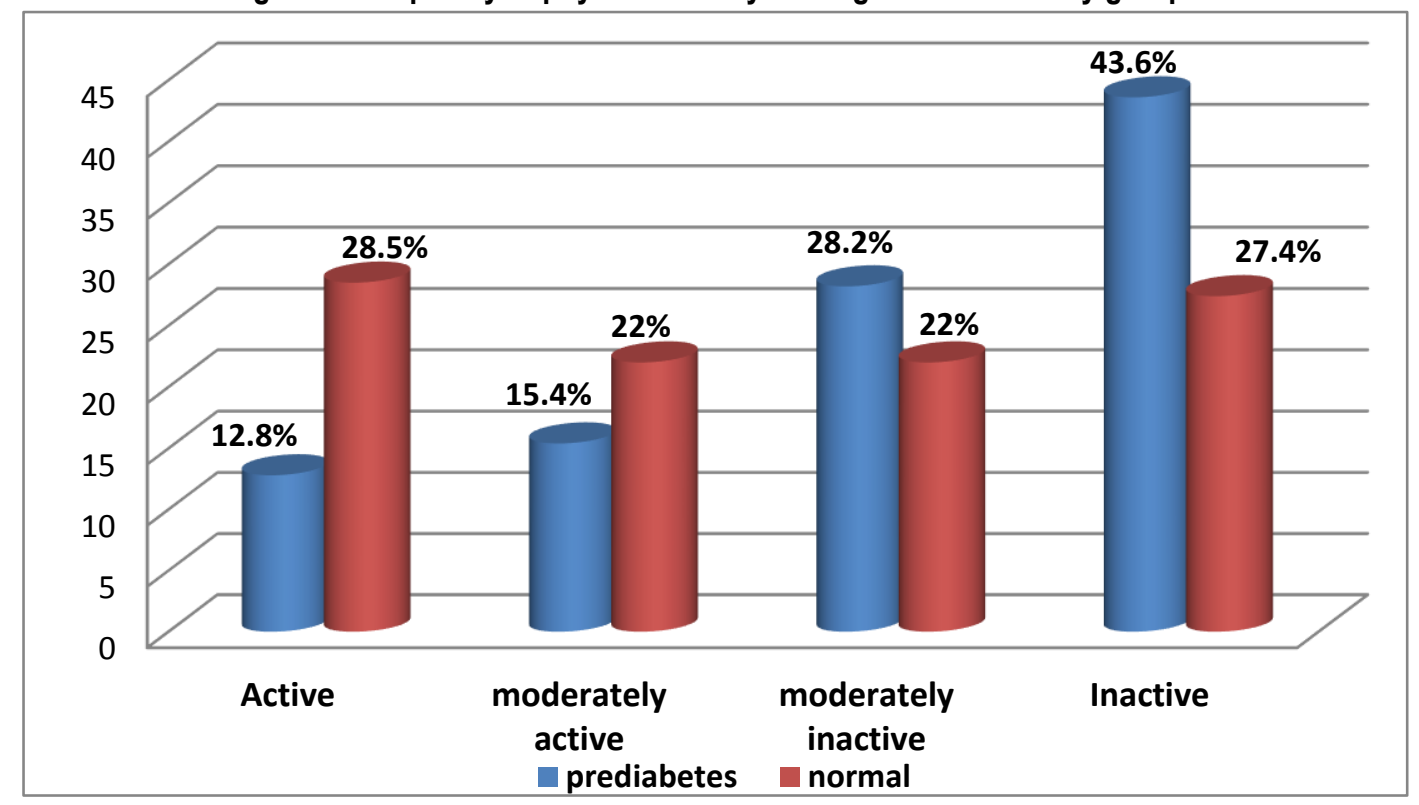




\section{DISCUSSION}

Pre-diabetes is a global public health issue and a major risk factor for developing type 2 diabetes mellitus. If pre-diabetes is diagnosed properly at the pre-diabetic stage and proper intervention is done, the incidence of pre-diabetes will decrease and patients will be able to live a healthier life..$^{1-5,9}$

This study aimed to detect the prevalence rate of pre-diabetes among adult population and to identify socio-demographic, lifestyle, medical factors as well as knowledge and attitude among pre-diabetics and compare them between the two group (prediabetes and normal). This comparison of associated risk factors was done to aid the development of measures specifically aimed at preventing pre-diabetes, along with the available health education program provided by the country's Ministry of Health and the special centers for diabetes. Thus, the comparison was conducted to increase awareness of pre-diabetes and consequently decrease the prevalence of pre-diabetes.

This study found that the prevalence of pre-diabetes in Makkah city is $17 \%$, which is consistent with the National Survey for Health Information of the Kingdom of Saudi Arabia (17\% among male and $15.5 \%$ among females). ${ }^{14}$ Our result is also relatively similar with those found in other countries, such as the U.S, New Zealand (16.1\%and $18.6 \%$, respectively), ${ }^{27,28}$ and slightly more than the result found in the study done in India (12.8\%).29 However, the prevalence of pre-diabetes found in the current study is lower than that in the study done in US by Menkeetal.,(38.0\%), ${ }^{30}$ and another study done on 899 South Asians living in America (33\%). ${ }^{31}$

The differences in the prevalence found in this study and other studies may be due to ethnicity, lifestyles and nutritional behaviors. Overall, our finding is strongly suggesting high prevalence of pre-diabetes among adults at Makkah City.

In this study, based on this analysis, we obtain a picture which reveals that pre-diabetes has a significant relation with several risk factors statistically, such as people with history of hypertension, physical inactivity, high body mass index and large waist circumference. To define potential risk factors, a logistic regression model was used. It showed that a history of hypertension and waist circumference had strong associations with pre-diabetes.

This result is consistent with those of many global studies. One of them reported Pre-diabetic status was associated with higher Body Mass Index, abnormal triglyceride levels, and hypertensive, but it was not associated consumption of fruit and vegetable and regular exercise.32,33 Also, some studies observed that the Predictors of pre-diabetes are male, old-age, high socio-economic status, low education level, hypertension, obesity, central obesity, and smoking. ${ }^{34}$ Moreover another study also has the same results; reported overweight adolescents had a 2.6-fold higher rate than those with normal weight (1.3-5.1). ${ }^{27}$ In multivariate analyses, an independent correlate of pre-diabetes was low exercise, which is in agreement with our results. ${ }^{31}$

In addition, studies done in the gulf area and they are in concord with our results. ${ }^{35,36}$ This consistency with neighboring countries may be due to the countries' similar factors, such as the countries' high-income status, high prevalence of obesity and greater prevalence of chronic disease such as diabetes, which has a greater burden on the health of the population.

Regarding food consumption and its association with prediabetes, we did not find a significant relationship. One explanation for this result could be the small sample size. The comparison of pre-diabetic and normal individuals' total energy and total energy produced by carbohydrates, proteins and fats showed no significant differences. However, in multiple logistic regression we observed that total energy, eating sweets are the most significant predictors among pre-diabetes group.

Regarding knowledge and attitudes toward pre-diabetes, our study shows that the levels of knowledge and attitudes between normal and pre-diabetes groups nearly similar in bad knowledge ( $40.3 \%$ vs. $43.6 \%$, respectively). This is in contrast to study done in U.S. and reported that the Participants were knowledgeable about their health and about pre-diabetes (diabetes knowledge score mean $=20.1, S D=1.1$ out of 32$).{ }^{37}$

It is difficult to compare with other studies due to the lack of studies on pre-diabetes knowledge and attitudes in our country and because we used a questionnaire that we constructed based on our literature review. Knowledge of pre-diabetics and normal individuals do not differ and this means there is a low level of awareness of pre-diabetes.

It is therefore essential to improve the knowledge and attitudes of the community through the development of educational tools, screening campaigns and models. These methods will require further in-depth research on knowledge and attitudes toward prediabetes.

In addition, in our study, gender and income have a positive impact on the knowledge of pre-diabetes. Females reported greater knowledge than men, and people with high income reported greater knowledge than those with low income. Our explanation may be that the female has more time for research about the knowledge regarding health and its needs to keep her health. Moreover high income people had resources to obtain the knowledge as internet and laptop.

As our study was conducted in primary health care centers, in Makkah City the results may not be truly representative of all prediabetes patients in the Kingdom of Saudi Arabia. The response rate of females was higher than that of men due to cultural issues because men typically work during the day; this could generate a selection bias. A substantial amount of our behavioral data, such as the data on diet and physical activity, is subject to recall and social desirability biases.

The strength of our study is that few previous studies on prediabetes were conducted and no similar study was done in Makkah city. In addition, our study tested many possible risk factors, including dietary habits, physical activity, knowledge, attitudes toward pre-diabetes and anthropometric measures (BMI and waist circumference). However, one limitation may be that our sample was collected from primary health care centers and the participants were patients seeking medical care, which affects the generalizability of the study. In addition the study relied on the patient's history of the conditions affecting $\mathrm{HgA} 1 \mathrm{c}$ test rather than laboratory tests.

Conclusively, a high prevalence of pre-diabetes status is reported in Makkah city, and it is associated with a history of hypertension, physical inactivity, obesity (high body mass index), central obesity (high waist circumference), total energy and eating sweets which are considered modifiable risk factors that may help guide prediabetes prevention interventions, as we know that pre-diabetes condition is considered high risk for diabetes incidence. Although it may be difficult to include all possible explanations for the 
increase in pre-diabetes prevalence, this study recommend the importance of increasing awareness of pre-diabetes and the need for effective health programs that encourage regular exercise and a healthy diet to decrease the prevalence of pre-diabetes in Saudi Arabia; such programs may lead to a future decrease in the prevalence of diabetes. Moreover we recommend further studies to detect another risk factors not mentioned in our study, knowledge of and attitudes toward pre-diabetes.

\section{REFERENCES}

1. Gillies $\mathrm{CL}$, Abrams KR, Lambert PC, Cooper NJ, Sutton AJ, Hsu RT, et al. Pharmacological and lifestyle interventions to prevent or delay type 2 diabetes in people with impaired glucose tolerance: systematic review and meta-analysis. BMJ. 2007; 334:299-302.

2. Henry P, Thomas F, Benetos A, Guize L. Impaired fasting glucose, blood pressure and cardiovascular disease mortality. Hypertension. 2002;40:458-63.

3. Milman S, Crandall JP. Mechanisms of vascular complications in prediabetes. Med Clin North Am. 2011; 95:309-25.

4. Rerkpattanapipat $P$, D’AgostinoJr RB, Link KM, Shahar E, Lima $J A$, Bluemke DA, et al. Location of arterial stiffening differs in those with impaired fasting glucose versus diabetes: implications for left ventricular hypertrophy from the multiethnic study of atherosclerosis. Diabetes. 2009; 58:946-53.

5. Kilmer G, Hughes E, Zhang X, Elam-Evans L. Diabetes and prediabetes: screening and prevalence among adults with coronary heart disease. Am J Prev Med. 2011; 40:159-65.

6. The American Diabetes Association, 2004. Diagnosis and classification of diabetes mellitus. Diabetes Care.;27 (suppl 1):S5S10.

7. Unwin N, Shaw J, Zimmet P, Alberti KG, 2002. Impaired glucose tolerance and impaired fasting glycaemia: the current status on definition and intervention. Diabet Med.;19;708-723.

8. Soewondo $P$, and Pramono LA Prevalence, characteristics and predictors of pre-diabetes in Indonesia. Med J Indones 2011; 20:283-94.

9. Zefferino S. Diffusion of Pre-diabetes Information through Healthcare Facilities. Thesis, Agriculture and Life Sciences, Social Sciences Committee, Communication Department of Cornell University, 2007.

10. Garber AJ, Handelsman Y, Einhorn D, Bergman DA, Bloomgarden Z, Fonseca V, et al. Diagnosis and Management of Prediabetes in the Continuum of Hyperglycemia-When Do the Risks of Diabetes Begin? A Consensus Statement from the American College of Endocrinology and the American Association of Clinical Endocrinologists. Endocr Pract. 2008;14(7):933-46.

11. Colagiuri S. Epidemiology of prediabetes. Med Clin North Am. 2011;95:299-307.

12. Vendrame F, Gottlieb PA. Prediabetes: prediction and prevention trials. Endocrinol Metab Clin North Am. 2004; 33:7592.

13. Chi PW, Cheng TYD, Shan PT, Hui LH, Shu LW. Increased mortality risks of pre-diabetes (impaired fasting glucose) in Taiwan. Diabetes Care. 2005; 28:2756-61.

14. Kingdom of Saudi Arabia. Ministry of Health. Available at: http://www.moh.gov.sa/en/Ministry/Statistics/Pages/healthinformat ics.aspx. [Last accessed November 21, 2015]
15. Alberti KG, Zimmet $P$, Shaw J. International Diabetes Federation: a consensus on Type 2 diabetes prevention. Diabet Med 2007; 24: 451-463.

16. Kingdom of Saudi Arabia. Ministry of Health. Available at: http://www.moh.gov.sa/en/Ministry/Statistics/Pages/healthinformat ics.aspx.Survey of health information. [Last accessed February 6, 2015]

17. Haftenberger M, Heuer T, Heidemann C, Kube F, Krems C, Mensink $G$. Relative validation of a food frequency questionnaire for national health and nutrition monitoring. Nutr J. 2010 Sep 14; 9:36.

18. Lillegaard IT, Overby NC, Andersen LF. Evaluation of a short food frequency questionnaire used among Norwegian children. Food Nutr Res. 2012;56.

19. National Health Institute (NHS). The general practice physical activity questionnaire (GPPAQ), 2006.

20. American diabetes association. Standards of medical care in diabetes-2016 Diabetes Care. 2016;39(S1):S1-S108.

21. Kilmer G, Hughes E, Zhang X, Elam-Evans L. Diabetes and prediabetes: screening and prevalence among adults with coronary heart disease. Am J Prev Med. 2011; 40:159-65.

22. Wardlaw GM Contemporary Nutrition. McGraw Hill, Boston, New York 2003; 348-349.

23. WHO: Obesity: preventing and managing the global epidemic. World Health Organ Tech Rep Ser 2000, 894:1-253. i-xii.

24. Universite Level. Waist circumference guidelines. Available at: http:/l www. myhealthywaist.org/evaluating-cmr/clinicaltools/waist-circumference-measurement-guidelines. [Last accessed October, 10, 2016]

25. Hemoglobin A1C Kit Flex Reagent package insert. Dimension Clinical Chemistry System. Siemens. Newark, DE. 2009/08/12.

26. The International Expert Committee. International Expert Committee report on the role of the $\mathrm{A} 1 \mathrm{C}$ assay in the diagnosis of diabetes. Diabetes Care. 2009; 32(7):1327-1334.

27. Li C, Ford ES, Zhao G, Mokdad AH.. Prevalence of prediabetes and its association with clustering of cardiometabolic risk factors and hyperinsulinemia among U.S. adolescents. Diabetes Care 2009; 32:342-347.

28. Coppell KJ, Mann JI, Williams SM, Jo E, Drury PL, Miller JC, Parnell WR (2013). Prevalence of diagnosed and undiagnosed diabetes and prediabetes in New Zealand: findings from the 2008/09 Adult Nutrition Survey.N. Z. Med. J. 1; 126(1370):23-42.

29. Anjana RM, Pradeepa R, Deepa M, Datta M, Sudha V et al.,. Prevalence of diabetes and pre-diabetes (impaired fasting glucose and/or impaired glucose tolerance) in urban and rural India: phase I results of the Indian Council of Medical Research- India DIAB (ICMR-INDIAB) study. Diabetologia. 2011; 54(12):3022-7.

30. Menke A, Casagrande S, Geiss $L$ and Cowie CC. Prevalence of and Trends in Diabetes Among Adults in the United States, 1988-2012. JAMA. 2015 8; 314 (10):1021-9.

31. Mainous AG, Tanner RJ, Baker R (2014). Prevalence of prediabetes in England from 2003 to 2011: population-based, crosssectional study. BMJ 4;4:e005002.

32. Soewondo P, Pramono LA. Prevalence, characteristics, and predictors of pre-diabetes in Indonesia. Med J Indones 2011; 20:283-94.

33. YI YS. Analysis of pre-diabetes-related factors in the elderly in Taiwan. Asia University 2012; 16:43:51. 
34. Al-Shafaee MA, Bhargava K, Al-Farsi YM, Mcilvenny S, AlMandhariA , Al-Adawi $S$, et al. Prevalence of pre-diabetes and associated risk factors in a $\mathrm{n}$ adult Omani population. Int $\mathrm{J}$ DiabDevCtries. 2011;31:166-174.

35. Al-Daghri NM, Al-Attas OS, Al-Rubeaan K, Mohieldin M, AlKatari $M$, Jones $A F$, et al. Serum leptin and its relation to anthropometric measures of obesity in pre-diabetic Saudis. Cardiovasc Diabetol. 2007 Jul 7;6:18

36. Bener A, Zirie M, Janahi IM, Al-Hamaq AO, Musallam M, Wareham NJ. Prevalence of diagnosed and undiagnosed diabetes mellitus and its risk factors in a population-based study of Qatar. Diabetes Res Clin Pract. 2009; 84:99-106.

37. Kolb JM, Kitos NR, Ramachandran A, Lin JL, and Mann DM. What do primary care pre-diabetes patients need? A baseline assessment of patients engaging in a technology-enhanced lifestyle intervention. J Bioinform Diabetes. 2014 Feb 2;1(1):4.

\section{Source of Support: Nil. Conflict of Interest: None Declared.}

Copyright: ( ) the author(s) and publisher. IJMRP is an official publication of Ibn Sina Academy of Medieval Medicine \& Sciences, registered in 2001 under Indian Trusts Act, 1882.

This is an open access article distributed under the terms of the Creative Commons Attribution Non-commercial License, which permits unrestricted non-commercial use, distribution, and reproduction in any medium, provided the original work is properly cited.

Cite this article as: Yousef Mohammed Turki, Amal A. Hegazy, Bahaa Abdulrahman Abaalkhail. Prevalence of Pre-Diabetes among Adults Attending Primary Health Care Centers, Makkah City, Saudi Arabia. Int J Med Res Prof. 2016; 2(6):128-36. DOI:10.21276/ijmrp.2016.2.6.026 